\title{
Power Mechanism and Measures for Economic Transformation and Upgrade in Henan under the Background of Steady Growth and Structural Adjustment
}

\author{
Bin $\mathrm{Li}$ \\ Department of Management \\ School of Business and Trade \\ Huanghe Science and Technology College \\ Zhengzhou, China
}

\begin{abstract}
Based on the analysis of main problems, advantages and disadvantages existing in the steady growth and structural adjustment in Henan province this article gives specially details of the trends and challenges that the economic transformation and upgrade of Henan faces with during the 13th five-year plan period, plus, considering the "three-big province" construction and the implementation of three national strategies, it specifies key fields and major drives for the economic transformation and upgrade under the background of steady growth and structural adjustment in the province and also raises targeted countermeasures and suggestions.
\end{abstract}

Keywords—steady growth and structural adjustment; economic transformation and upgrade; Henan

\section{INTRODUCTION}

Nowadays, in face of the enormous pressure of economic downturn, Henan has attracted more and more eyeballs for its economic growth prospect and economic transformation trend. Seen overall, the 13th five-year period is a key "window stage" for the economic transformation and upgrade in Henan, if failing to well grasp the strategic opportunities for economic transformation, it will be in a difficulty for continue the sound situation for the economic and social development; If the historic opportunities are caught and fully considered, it will place a solid foundation for the sustainable economic growth in the province over the coming 20 years. Therefore, it is a must for us to shift to long term from short time, to quality from quantity, to structure from speed and to system environment from policies, aiming at the strategic breakthrough of the economic transformation and upgrade by 2020 and deeply planning the 13th five-year development for the province.

Project support: 2016 soft science project (Research on Problems Relative to Stabilizing Growth Rate and Adjusting Structure in Henan under the New Normal), project No: 162400410108 .

\section{TRENDS AND CHALLENGES FOR THE ECONOMIC TRANSFORMATION AND UPGRADE IN HENAN DURING THE 13TH FIVE-YEAR PLAN PERIOD}

During the 13th five-year plan period, the acceleration of economic transformation and upgrade is a practical selection adjusted automatically to meet the New Normal of economy and a strategic option to automatically lead the New Normal of economy. In order to promote the economic transformation and upgrade, the key point is to correctly judge the economic development trend in the province, well clearly know the future, catch the development opportunities, as well as actively react to challenges, improve the occasion and follow the trends

\section{A. Three Historic Trends That Economic Transformation and Upgrade Faces}

"Made in Heann" is developing toward "Created in Henan", which is the trend of industrial transformation and upgrade. As a province large in population, in order to change from a province large in manufacturing to an intellectualized province large in advanced manufacturing, the industry of the province is faced with a significant historic opportunity for transformation and upgrade.

Henan is in an upgrade trend developing from a rural society to an urban society. At present, the urbanization construction in the province is in a rapid progress, during the 13th five-year plan period, the population urbanization rate will break through $50 \%$, and the it will enter an urban society, the urbanization is in face of opportunities and challenges.

Urban and rural residents are in an upgrade trend of consumption structure which develops to service consumption from material consumption. With the coming of an urban society and an overall well-off society, the demands for material consumption by urban and rural residents are basically met, in the meantime, the service-oriented consumption is growing and the survival-oriented consumption is upgraded to a development-oriented consumption and the 
traditional consumption is transformed to a differentiated and personalized consumption.

\section{B. Four Challenges Faced by the Economic Transformation and Upgrade}

Improper positions exit between governments and markets, during the economic development in Henan, the government has been stronger in the economic regulation, which weakens the market functions, restraining the emergence of innovation abilities and failing to form a commercial mode where technical achievements are converted into actual industries, consequently, it is almost impossible to convert from the "Made in Henan" to "Created in Henan".

The demographic dividend stage is disappearing, driven by comparative gains, most of right-age laborers seek jobs at the Pearl River Delta, the Yangtze River Delta as well as BeijingTianjin-Hebei, plus, the aging population is not a-distant future, the rising labor costs as well as the surplus laborers in rural areas in Henan who are not as many as they are thought, the demographic dividend stage will come to an end.

Unbalance in industrial structure. The tertiary industry develops more slowly than others in the province, in 2014, the added value of the tertiary industry occupied $36.9 \%$ only of the GDP, 11.3 percent falling behind the national average level; and proportion of three industries was 11.9: 51.2: 36.9, which turned out that the industrial structure was in a severe imbalance.

Resources and environmental problems are highlighted. Over the past years, the low-tech and extensive economic development pattern and the extended urbanization pattern have brought heavier pressure to the environment and the energy and water consumptions per GDP are huge, and it becomes urgent to solve the challenges relative to resources and environment.

\section{MAKE THE EMPHASIS TO INCUBATE THE POWER FOR THE ECONOMIC TRANSFORMATION AND UPGRADE IN HENAN DURING THE 13TH FIVE-YEAR PLAN PERIOD}

\section{A. Core Power: Industrial Structure Shift}

The industrial structure shift will be a sound promotion and drive to the economic transformation and upgrade. And it has been a core power to push the co-development of three industries, incubate advanced modern industrial systems and create a network-based industrial development.

Active development of advanced manufacturing industry: featuring high technical contents, high added value, intensive capital, low energy consumption, resource saving as well as self-owned intellectual property rights and solid foundation for the economic transformation and upgrade. Henan is expected to exert the comparative advantages of its own, meticulously select backbone industries, strive to develop high-tech industries to form an industrial high ground; borrow advanced technologies to rebuild traditional manufacturing industries; and rapidly develop the Xinxiang - Zhengzhou - Xuchang and Zhengzhou - Luoyang T-shaped advanced manufacturing industry network belts.
Acceleration of modern service industry: Modern service industry goes like a booster for the economic transformation and upgrade, only the tertiary industry gets greatly developed, can the power of economic growth be changed to consumer demand from investment demand and make the economic transformation and upgrade come true. While pushing the modern service industry, the high-tech service shall be highlighted. The Zhengzhou Airport Comprehensive Pilot Area and one belt one road related cities shall be fully utilized to develop modern logistics systems and modern shipping hub, driving Luoyang and Nanyang as pilot areas for the pan tourism development.

Integrated agricultural modernization: Laws of agricultural modernization shall be followed to push the agricultural development to markets, mechanization, ecotype, internationalization and high efficiency, make the agricultural structure and upgrade be quickened; put more investment to human capital in rural areas, bring more agricultural productivity and farming income; erect Internet to ever corner in rural areas and push the agricultural development via IT; develop more lands for organic farms, advocate tourism farms; better the macroeconomic structure of agricultural production and economy, and make the nutrition supply better to service modern agriculture in the province.

\section{B. Direct Power: New-Type Urbanization}

During the 13th five-year period, the population urbanization rate will break through $50 \%$ and Henan will enter an urban society and the huge internal demand hidden in urbanization will be fully released, it can be surely said that the new-type urbanization is still the largest dividend for its development and also a direct power for the economic transformation and upgrade.

In order to better the industry-city integration" mechanism and steadily push the connotative urbanization, it needs to start with the space integration, function restructuring, size optimization and more to perfect the urban systems across the province; aim at rational and advanced industrial structures and integration, intensify the urban industrial supports; build more energy, electricity and water supply networking, create a logistics network, share information resources, improve the integrated transport system and realize co-development and interactive connection among infrastructures between urban areas;

Strengthen the control upon water pollution, air pollution, land pollution, improve the ecological compensation mechanism, expand comprehensive bearing capacity of urban environment; renovate the household registration system, land system, complete the employment system, regulate the investment and financing mechanisms, perfect the social security system, push the fair education and perfect the population migration mechanism in urban new areas.

\section{Internal Power: Innovative Drive}

Under the New Normal, the innovation driving growth is a new power source for the sustainable economic development and a core handle for the industrial transformation and upgrade and for the industrial boom. The innovation will help to 
develop the intellectual property rights, forming a comprehensive innovative ecological system, which will increase the output of production factors, create potential wealth and employment opportunities, and realize the intensive economic growth.

The enterprises localized in Henan are encouraged to create "innovative stations" in cities where innovative and creative talents are gathered such as Shanghai, Beijing, Tianjin, Wuhan, $\mathrm{Xi}$ 'an and more to promote the coupling in employment, information, technology, knowledge and even enterprises between Henan and other provinces or regions, forming a value chain-based interconnecting, co-existing innovative network inside and outside the province. Strengthen the construction of soft and hard environment in core cities as Zhengzhou, invite investments as per industrial chains and value chains, attract multinational headquarters and advanced manufacturing headquarters to settle, and promote the connection, supporting, exchange and cooperation between local enterprises and those which have settled there. Push the connection of innovative activities on the value chains of six carriers namely "authority, production, research, study, citizen, media" to build an internal collaborative innovation network in the province. And create a new and high efficiency innovative network system through foreign connection, introduction and internal connection mechanism, achieve the investment-driven economic development, with the factor driven converted into efficiency-driven and innovation driven, reshape the economic competitiveness in the province and create a new economic development pattern on the core concept of "Enrich the people via start-up, power the province via innovation, full employment, fair distribution".

\section{Accelerating Power: Economic Globalization}

Within an open economic environment, the economic globalization has played an important role in the economic transformation and upgrade in Henan. Accordingly it is a must to intensify the reform and opening up to promote the Central Plains Economic Zone for its' full integration to national "one road one belt" strategy, break through the geographical boundaries and achieve the free flow of factors such as goods, labor, technology, capital in a wider space, speed up the pace of Henan to integrate its industries to the global production and trade systems, achieving the optimized allocation of resources.

Zhengzhou is located where Longhai Railway and BeijingGuangzhou Railway meet, owning a unique geographical advantage to connect the east with the west, the north with the south, a strategic support for the new Silk Road economic belt and the industrial heartland of the maritime Silk Road, so Zhengzhou shall be built under the standard of a national central city. Intensify the cluster and radiation of Zhengzhou, incubate featured and advantageous industrial clusters such as aviation manufacturing cluster and international logistics clusters; make good use of the two gilded signboards namely Inland Opening-up Economy Pilot Area and Zhengzhou Airport Economic Comprehensive Pilot Zone, speed up the application for the Middle Region Free Trade Pilot Area in Zhengzhou, and build a Zhengzhou-based silk road channel via air, network and inland; Build Zhengzhou into an international metropolis integrating barrier-free international trade and investment, logistics cooperation, cultural exchanges, top-end exhibition and the like and create the Central Plains Economic Zone into a core block for opening up in the middle region.

\section{E. Key Power: Green Economy}

The ecological civilization, a part of economic development together with the green economy shall be an important means to promote the reform, adjust the structure and benefit the people, and a key power source for the economic transformation and upgrade under the New Normal.

On the one hand, speed up the ecology-based economic development, carry out the new-type industrialization, advocate the green product design, complete the green supply chains, eliminate the industries of high material consumption, high energy consumption and high pollution, create a new, green and low-carbon industrial system; build an eco-city, ecological parks, push the circular economy and energy saving service, achieve the reduction, energy saving, pollution control and waste recycling; set up a green view of life, and accelerate the green process from production to consumption.

On the other hand, advocate the eco-economy, rationally retain, use, develop and protect ecological resources, well protect the ecosystems, enhance the quality and quantity of natural assets, optimize the ecological service, and achieve the green economic growth in the province through ecological resources, pricing and capitalization of ecological assets, paid ecological service and ecological compensation.

\section{SUGGESTIONS ON THE ECONOMIC TRANSFORMATION AND UPGRADE IN HENAN DURING THE 13TH FIVE-YEAR PLAN PERIOD}

\section{A. Normalize the Relations between Authorities and Markets}

In order to accelerate the economic transformation and upgrade in the province, it needs to exert the decisive role of market allocation of resources and the maximization of the governmental macro-management and regulation. On the one hand, decentralize powers to the markets, and the decrease of government powers will bring the increased market vitality. On the other hand, authorities are expected to drive the egovernment affairs, improve the efficiency of dynamic governance, and provide guide and service in the public service, market supervision, macro-control, environmental protection so as to guarantee the decisive role of the markets to exert and enhance the market level.

\section{B. Systematic Integration of Public Policies}

First of all, it needs to integrate the development plan for the economic transformation and upgrade in Henan during the 13th Five-Year Plan period. The development plan needs not only a vertical professional depth, but also a horizontal crossfield coordination, and even a systematic strategic thinking to lead so as to meet the economic transformation and upgrade. Second, it needs to integrate industrial policies, employment policies as well as investment and financing policies; exert the inducing functions of high-tech industrial development policies, with social employment policies, innovative 
investment and financing services considered, so as to establish a complete policy system integrating "industry employment - investment and financing". In addition, it needs to work together to promote the reforms of social security policies, public housing policies, education policies, land policies and household registration and exert its role in design, standards, intervention and security so as to push the economic transformation and upgrade.

\section{Create A Friendly Environment for Innovation and Start- $U p$}

Innovative spirit and start-up activity are key driving factors for the economic transformation and upgrade in the province. It needs to create a friendly innovative and start-up environment, incubate new \& hi-tech start-up parks, enhance the abilities of independent innovation, promote the development of leading industries, and make activities such as innovation, start-up and creativity the mainstream in the economic and social life and then achieve the goal of expanding employment and transforming the economic grow pattern. Accelerate the reform of science and technology systems, improve the environment for start-up and investment, promote the construction of credit systems. Strengthen the relations between start-up enterprises via start-up parks, startup incubators, productivity promotion centers, form a start-up network with cluster effect and size effect so as to push the commercialization and industrialization of innovative achievements. Release start-up policies with clear goals and niche highlighted to support the network and create a flexible environment for innovation and start-up, incubate emerging start-up enterprise clusters and push the endogenous growth of economy.

\section{Establish Systems for the Emergency of Talent Dividends}

Whether the economic development will succeed or not in the future shall depend on the number of quality talents in the province, and the conversion to talent dividends from demographic dividends will be a guarantee for the economic transformation and upgrade. For a long time, due to the development lag of the tertiary industry and the system restriction in the province, top-end talents are unable to adapt to start-up and employment, as a result, most of them left Henan for other provinces and abroad. So it is a must to deepen the reform of talent systems, build a culture and atmosphere encouraging venture and exploration and allowing failure and comparatively free to incubate. Raise the HR development and management, enhance the quality of population in the province, achieve the transformation and upgrade of the labor element, activate and release the local talent dividends; and release measures to invite talents and brainstorms via financial support, house purchase subsidies, career incentives and the like, attracting high-end talents around the world to the province for start-up, employment and making contributions. Perfect the legal environment for the high-end talent flow, carry out the property rights system of talent dividends, complete the social security system for highend talents, and create build an institutional environment with a talent dividend emerging needed by the economic transformation and upgrade.

\section{CONCLUSION}

After systematically analyzing the economic transformation and upgrade in Henan, the author draws a conclusion: under the background of steady growth and structural adjustment, the economic transformation and upgrade in Henan is faced with four challenges including improper positions between governments and markets, demographic dividend disappearing, imbalanced industrial structure, highlighted resource and environment problems; and it needs to start with industrial structure shift, new-type urbanization, innovative drive, internationalized economy and green economy to set up a power mechanism for the economic transformation and upgrade in the province; and it is suggested to well arrange the relations between governments and markets, integrate public policies systematically, create a friendly innovative and start-up environment and establish systems for the emergence of talent dividends, as well as issue relevant policies so as to promote the economic transformation and upgrade.

\section{REFERENCES}

[1] Academy of Macroeconomic Research Economic Trend Research Group, Liu Xueyan, Du Feilun, et al, No Changes in Foundations for Long Term Economic Growth-2015 Economic Situation Analysis and Outlook for 2016 [J] Macroeconomic Management, 2016(1):11-13.

[2] He Weihua, Research on Power for Steady Economic Growth and Structural Adjustment in Henan under the New Normal [J] Journal of Henan Institute of Science and Technology, 2015(11):1-5.

[3] Yu Xin'an, 2014 Henan Blue Book, Economy-Report of Economic Development in Henan [M], Social Sciences Academic Press, 2013 